\title{
El Diccionario etimológico de Rodolfo Lenz (1905-1910): una aproximación glotopolítica
}

\author{
Valentina Cáceres ${ }^{1}$ \\ Universidad de Chile, Chile \\ José Miguel Ortiz \\ Investigador independiente, Chile \\ Darío Rojas ${ }^{3}$ \\ Universidad de Chile, Chile
}

\begin{abstract}
Resumen
Desde un enfoque glotopolítico (que asume una relación estrecha entre construcción de conocimientos sobre el lenguaje y poder), analizamos materiales publicados e inéditos que nos permiten sostener que el Diccionario etimológico de voces chilenas derivadas de lenguas indígenas americanas (1905-1910) de Rodolfo Lenz, lejos de constituir un gesto reivindicativo del mapuzugun o de las variedades de castellano marcadas por el contacto con esta lengua, forma parte orgánica del dispositivo estatal chileno de colonización de la Araucanía. Por tanto es una herramienta al servicio de la
\end{abstract}

\footnotetext{
1 Para correspondencia, dirigirse a: Valentina Cáceres (valentina.caceres@ug.uchile.cl), Universidad de Chile, Facultad de Filosofía y Humanidades, Departamento de Lingüística. Av. Capitán Ignacio Carrera Pinto 1025, piso 3, Ñuñoa, Santiago.

Para correspondencia, dirigirse a: José Miguel Ortiz (kmortizb@gmail.com).

Para correspondencia, dirigirse a: Darío Rojas (darioroj@uchile.cl), Universidad de Chile, Facultad de Filosofía y Humanidades, Departamento de Lingüística. Av. Capitán Ignacio Carrera Pinto 1025, piso 3, Nuñoa, Santiago.
} 
dominación del pueblo mapuche y de los sectores subalternos de la nación. El Diccionario, a pesar de su postura descriptivista que lo hace sobresalir frente a la tradición lexicográfica normativista chilena del siglo XIX, sirve de vehículo para una representación ideológica del castellano vulgar chileno en términos de una diferencia concebida como déficit, marcada fundamentalmente por la influencia del mapuzugun. Ampliamos el análisis del propio texto del Diccionario (en particular sus preliminares) mediante el examen de dos zonas del archivo donde se manifiestan las condiciones de producción y circulación de la obra: los materiales que apuntan a su inscripción en las investigaciones asociadas a la Sociedad de Folklore Chileno y las reseñas, cartas y otros documentos que dan cuenta de la recepción que el Diccionario tuvo en los círculos especializados.

Palabras clave: lexicografía, lexicografía crítica, glotopolítica, contacto mapuzugun-castellano, castellano chileno.

\title{
Rudolf LenZ's Diccionario ETIMOlÓGico (1905-1910): A GLOTTOPOLITICAL APPROACH
}

\begin{abstract}
From a glottopolitical approach (which assumes a close relationship between the construction of knowledge about language and power), we analyze published and unpublished materials that allow us to maintain that Rudolf Lenz's Diccionario etimológico de voces chilenas derivadas de lenguas indigenas americanas (1905-1910), far from constituting a claiming gesture of Mapuzugun or the varieties of Castilian marked by contact with this language, is an organic part of the Chilean state's project of colonization of the Araucanía and is therefore a tool at the service of the domination of the Mapuche people and the subaltern sectors of the nation. The Diccionario etimológico despite its descriptive posture that makes it stand out against the Chilean normativist lexicographic tradition of the 19th century, serves as a vehicle for an ideological representation of Chilean vulgar Castilian in terms of a difference conceived as a deficit, marked mainly by the influence of Mapuzugun. We extend the analysis of the dictionary text itself (particularly its preliminary sections) by examining two areas of the archive where the conditions of production and circulation of the work are manifested: the materials that point to its belonging in the investigations associated with the Society of Chilean Folklore and the reviews, letters and other documents that account for the reception that the Diccionario had in specialized circles.
\end{abstract}


Keywords: lexicography, critical lexicography, glottopolitics, Mapuzugun-Spanish contact, Chilean Spanish.

Recibido: $15 / 01 / 2020 \quad$ Aceptado: $11 / 03 / 2020$

\section{OBJETIVOS Y ENFOQUE DEL ESTUDIO ${ }^{4}$}

Las representaciones ideológicas que en el Chile del largo siglo XIX se construyeron discursivamente acerca de las consecuencias del contacto mapuzugun-castellano en el castellano chileno, especialmente aquellas que circularon inmediatamente después de la guerra que el Estado chileno emprendió contra el pueblo mapuche con el fin de ocupar la Araucanía (1861-1883), merecen un estudio crítico que contribuya a desmontar los soportes ideológicos de las estructuras de dominación material y simbólica que la nación chilena ha ido articulando desde su constitución con el fin de subyugar al pueblo mapuche y a los sectores subalternos de la nación chilena. Estas representaciones en particular, aunque tienen como agentes principales a la élite castellanohablante y tratan fundamentalmente sobre el castellano chileno, repercuten más allá de este grupo y de la variedad lingüística hegemónica, pues la posición de poder de sus enunciadores les permitió naturalizarlas como un sentido común transmitido a través de la escuela, la prensa y otras instituciones sociales, y tomar el control de la asignación de valor a las variedades lingüísticas (castellanas y no castellanas) habladas y escritas en la ecología sociolingüística chilena. Se trata, en este sentido, de un discurso hegemónico o ideología dominante (Bourdieu y Boltanski

\footnotetext{
${ }^{4}$ Este trabajo se inscribe en los proyectos FONDECYT Regular 1170419 "Mediación lingüístico-cultural y castellanización en los ámbitos de contacto mapudungun-castellano derivados del proceso de chilenización de la Araucanía: producción lingüística y etnográfica, administración de justicia y escolarización (1880-1930)" (CONICYT, Gobierno de Chile), y H850 "Filología, lingüística y archivo: aportes hacia una historia política de la lengua entre Europa y América Latina (mediados del siglo XIX-comienzos del siglo XX)" (Universidad Nacional de La Plata). Queremos expresar nuestro especial agradecimiento al profesor René Zúñiga, responsable del Fondo Lenz de la Universidad Metropolitana de Ciencias de la Educación (Santiago, Chile), por facilitarnos el acceso a documentación inédita o difícil de encontrar, y relevante para el tema de este trabajo.Agradecemos asimismo a Juan Ennis, quien hizo una lectura detallada de una versión preliminar de este texto y contribuyó con valiosos comentarios a su mejora.
} 
2009); la esfera del lenguaje y las lenguas, en este caso, no es más que una superficie de expresión de un conflicto de naturaleza política.

El tema de la influencia del mapuzugun en el castellano cobró prominencia especial en los círculos intelectuales en la última década del XIX con la llegada del alemán Rodolfo Lenz al Instituto Pedagógico de la Universidad de Chile, quien explicó las particularidades del castellano chileno como influencia del contacto con el mapuzugun durante la época colonial. Las reacciones que suscitó la tesis "araucanista" de Lenz no pueden entenderse cabalmente si no se tienen en cuenta los acontecimientos que en las décadas inmediatamente anteriores habían configurado la relación entre los mapuche y el Estado chileno. Entre 1861 y 1883, este llevó adelante la Ocupación de la Araucanía, una empresa militar, política y económica de colonización y aculturación de los territorios mapuche ubicados al sur del río Biobío, la cual tuvo, entre otras consecuencias, un importante retroceso de la vitalidad del mapuzugun ( $c f$. Zúñiga y Olate 2017, para el estado actual de la lengua).

En relación con este contexto histórico y con esta empresa en particular, la representación ideológica de las lenguas y sus interrelaciones cobran un claro sentido (gloto)político, al servir de vehículo para naturalizar posiciones de dominación y subordinación entre sus respectivos hablantes. Es de especial interés, en tal caso, poner atención sobre las representaciones metalingüísticas articuladas desde el campo del saber especializado, por su estrecha relación con el poder y la autoridad estatal. El enfoque de la glotopolítica (Del Valle 2017), que adoptamos en nuestra propuesta conlleva cuestionar la supuesta neutralidad ideológica y política de las representaciones y prácticas metalingüísticas de los lingüistas, lo cual es especialmente relevante cuando estos son agentes del Estado o se encuentran de alguna manera (abierta o solapadamente) al servicio del interés de las clases dominantes, situándose en "la intersección del campo intelectual con el campo del poder". (Bourdieu y Boltanski 2009: 13)

Esta premisa (la condición ideológica y política del saber lingüístico especializado) no es más que una aplicación particular de la premisa general de la naturaleza política del conocimiento. De acuerdo con Michel Pecheux, la emergencia histórica de la ciencia es "el efecto (y la parte) de un proceso histórico determinado en última instancia por la producción económica misma" (Pecheux [1975] 2017: 164). No solo las revoluciones científicas, sino más ampliamente los discursos de la ciencia en cualquier momento "no están apartad[o]s de la historia (de la lucha de clases): constituyen 'desprendimientos' especializados de las ideologías prácticas en el terreno de la producción de conocimientos" (ibid.). Igualmente, Aronowitz (1988) muestra cómo la ciencia moderna se construye a sí misma como autoridad y como "verdad" mediante, por un lado, el ocultamiento de la influencia 
de valores y contextos materiales específicos y, por otro, un énfasis en la objetividad de su método; es decir, a través de un proceso de ocultamiento de lo político o de blanqueamiento ideológico. Al presentarse no solo como la principal sino como la única forma legítima de conocimiento, como la manera de acceder a la "verdad", la ciencia se convierte en una fuente de legitimidad y de poder autoevidente e incuestionable al servicio de las clases dominantes y los que gobiernan, que consiguen a través de ella naturalizar $s u$ verdad como la verdad.

Laurendeau (1990) aplica el razonamiento anterior a la historiografía de las ciencias del lenguaje, proponiendo que cualquier disciplina, escuela, paradigma o teoría sobre el lenguaje puede entenderse como una emergencia surgida de las condiciones específicas de la praxis de una sociedad dada, entre las que ocupan un lugar especial, por supuesto, el modo de producción hegemónico (el capitalismo, para el caso de la lingüística moderna; $c f$. Heller y McElhinny 2017) y la manera en que se desarrolla la lucha de clases en ese momento histórico. Situada desde el punto de vista de lo que Laurendeau denomina teoría de la emergencia, la historiografía de la lingüística "sees in every school of linguistics an indirect and relatively autonomous product of concrete socio-historical contexts" (Laurendeau 1990: 212) y considera que "all intellectual representation (ideology, theory, science) is, from the historical point of view, an emergence erupting from history, i.e. from the specific conditions of the praxis of a given society" (ibid.). Las directrices generales de esta consideración crítica y contextualista de la historia de las ciencias del lenguaje, que las concibe como una práctica ineludiblemente política, son compartidas por Koerner (2001) y Swiggers (2018), además de por Del Valle (2019), quien destaca:

[B]oth language and the institutions around it are always embedded in history. Disciplines, co-constitutive with such objects, emerge and develop in tandem with struggles over specific social needs and demands, alternative epistemic paradigms, and differential material conditions for the production and distribution of knowledge. (Del Valle 2019)

A partir de estas coordenadas teóricas, en el presente trabajo nos proponemos estudiar desde un enfoque glotopolítico el Diccionario etimológico de las voces chilenas derivadas de lenguas indígenas americanas (1905-1910) de Rodolfo Lenz, uno de los pilares de su inconcluso proyecto de estudio del contacto lingüístico y cultural castellano-mapuche, que constituye, por alcance y extensión, la más voluminosa manifestación del proyecto intelectual de Lenz. No forma parte de nuestros objetivos estudiar la estructura textual del Diccionario (para lo cual $c f$. Ferreccio 1979 y Chávez 
2011), sino abordarlo como discurso y como acción glotopolítica, es decir, como intervención en el espacio público del lenguaje.

En consecuencia, escudriñaremos, en primer lugar, en el contexto disciplinar y político-cultural en el cual emerge esta obra, poniendo especial énfasis en el lugar que este diccionario ocupa en la historia de los estudios del lenguaje en Chile, así como en las condiciones de producción y circulación de la obra. Junto con poner de relieve la recepción del Diccionario en el ámbito especializado, la que creemos permite apreciar el efecto ideológico de su publicación, nos interesa destacar especialmente en este trabajo una arista hasta ahora poco considerada en los estudios sobre el Diccionario de Lenz: su relación con la labor de la Sociedad de Folklore Chileno, institución fundada por el propio Lenz en 1909, y que cumple un rol importante en el dispositivo de levantamiento de conocimientos políticamente útiles por parte del Estado chileno embarcado en una colonización interna y expansión territorial. De este modo, queremos cumplir el requisito metodológico del enfoque glotopolítico (Arnoux y Nothstein 2014: 9) relativo a considerar el texto como discurso, es decir, como "articulación de un texto y un lugar social" (cit. en Arnoux 2006: 15), o, dicho de otro modo, como una práctica lingüística y social inserta en un contexto específico, que debe ser pensada "históricamente". (Meirinho-Guede y Del Valle 2018: 5)

En segundo lugar, estudiamos los principales ejes discursivos que articulan la ideología lingüistica (Del Valle y Meirinho-Guede 2016) en que se sustenta el diccionario, es decir, las representaciones tanto sobre el mapuzugun como sobre el castellano chileno y sus hablantes que se movilizan en los textos preliminares del diccionario. Adoptamos, siguiendo a Thompson (1984), una concepción crítica de la ideología, la que, a partir del entendimiento de dicho constructo como "action-oriented sets of beliefs which are organized into coherent systems" (Thompson 1984: 78), al mismo tiempo las comprende como inextricablemente relacionadas con el poder por su rol protagónico en la mantención de relaciones sistemáticamente asimétricas dentro de una determinada comunidad de individuos (lo que Thompson entiende precisamente por dominación; cf. 1984: 130) y la legitimación del poder de un grupo o clase social. Así, las ideologías lingüísticas serían "sistemas de ideas que articulan nociones del lenguaje, las lenguas, el habla y/o la comunicación con formaciones culturales, políticas y/o sociales específicas". (Del Valle 2007, cit. en Del Valle y MeirinhoGuede 2016: 629)

Finalmente, sobre la base de los elementos anteriores, proponemos una interpretación del significado glotopolítico que pudo haber tenido la publicación de este diccionario, entendiéndola como una intervención en el espacio público del lenguaje motivada por el posicionamiento político de su 
enunciador y de las instituciones en las que este estaba inserto. En este punto, tomamos distancia crítica frente a lecturas de inclinación hagiográfica que ponen de relieve el "aporte" de Lenz a las ciencias del lenguaje o a los propios grupos humanos que estudió (como hacen Chávez 2011 o Sánchez 2013). Podría eventualmente comprobarse que Lenz en efecto sentía "simpatía y preocupación por la 'gente de la tierra"” (Sánchez 2013: 110), así como podría incluso afirmarse de buena fe que "difícilmente habría encontrado la gente mapuche [...] un mejor defensor [que Lenz]" (Sánchez 2013: 111), pero aceptar estas aseveraciones sin mayor crítica sería desconocer que, más allá de las intenciones, la obra de Lenz pudo haber tenido en su contexto un efecto que escapaba a sus buenos deseos. Como señala Errington a propósito de la lingüística colonial europea, "linguists' work had meanings and uses which outstripped their own purposes and understandings. Taking lives of their own when, as texts, they circulated among different readers in different societies, and served different projects". (Errington 2008: 12)

Asimismo, si, como haremos, se asumen algunos de los principios fundamentales de los estudios críticos del discurso lexicográfico (Chen 2019), poco sentido tiene considerar que por tratarse de una obra de inclinación "científica" o descriptivista (como argumenta Chávez 2011), el Diccionario de Lenz deja de tener un papel en la construcción de la ideología dominante, lo cual además implica soslayar que Lenz era, después de todo y considerando la complejidad de su lugar institucional (que nunca fue completamente estable, sino por el contrario, siempre fue contestado), un agente del Estado chileno. Entre los principios teóricos que es necesario considerar se encuentran, primero, el que "lexicography and its products, dictionaries, are never value-free, apolitical or asocial. Instead, they are subject to ideology, power, and politics" (Chen 2019: 362); segundo, que "any lexicographical text (the dictionary proper) is a social act, a product of the socio-political and historical context in which it exists" (Chen 2019: 373); y, tercero, que "objectivity and authority of the dictionary is a discursive construct" (ibid.). En oposición a una posible lectura que quiera destacar la contribución que haya hecho el Diccionario de Lenz a "reivindicar el estudio de una lengua marginada" (Chávez 2011: 98) y a "dar cuenta de [la] transculturalidad en Chile" (Chávez 2011: 98), nuestra interpretación pondrá de relieve el papel político que desempeñó el Diccionario etimológico de Lenz en el proceso de castellanización de la Araucanía, de retroceso funcional del mapuzugun y de dominación del Estado chileno sobre los mapuche, operando como parte integral del dispositivo colonizador republicano y de constitución de un régimen de normatividad lingüística y social en el contexto político y social en transformación del entresiglo. 


\section{LA EMERGENCIA Y RECEPCIÓN DEL DICCIONARIO ETIMOLÓGICO DE LENZ}

\subsection{El DicCionario etimológico, La ROMANística Y LA LINGÜÍSTICA HISTÓRICA}

Dado que los antecedentes de la llegada del lingüista alemán Rodolfo Lenz al recién creado Instituto Pedagógico de la Universidad de Chile en 1890 son de sobra sabidos, así como bien conocidos son los aspectos globales de su obra, nos permitiremos ahorrarnos su recuento detallado ( $c f$. Escudero 1963 para un panorama general). Baste con destacar que Lenz fue el protagonista de una fractura en la tradición de los estudios del lenguaje en Chile, en la última década del XIX y las primeras del XX. Si en el siglo XIX predominó la idea de Andrés Bello de que el estudio del lenguaje suponía una preocupación por construir la unidad del idioma en torno a un castellano "correcto" (Rojas 2017), con la llegada de Lenz se introduce una divergencia en los supuestos tanto epistemológicos como metodológicos de la disciplina en el país. La hipótesis araucanista de Lenz, que proponía una influencia determinante del mapuzugun en el castellano chileno, y su interés predominante por el lenguaje vivo, oral, del "pueblo" chileno, significó un quiebre con la tradición filológica chilena, por introducir a los sectores subalternos en la construcción de un imaginario de la lengua nacional (siguiendo la tradición filológica alemana en la que él mismo se había formado) y por además pretender estudiar sus formas de lenguaje en sus propios términos, y no necesariamente en relación con su supuesta condición de "incorrecciones" o "desviaciones" del estándar. Precisamente por su carácter rupturista, Lenz, a pesar de contar con el respaldo del Estado, se enfrentó con importantes resistencias y acusaciones malintencionadas de parte de la intelectualidad chilena afín al hispanismo, que negaba o minimizaba la parte indígena de la formación de la nación. (Pavez 2015)

El Diccionario etimológico de Lenz significa "la consolidación del paradigma indigenista que formula Lenz para el español de Chile y como apuesta para el indigenismo lingüístico en América" (Pavez 2015: 120). Debe tenerse en cuenta que el interés de Lenz por el contacto castellanomapuzugun se inscribe en su condición de agente colonial de la ciencia europea. Específicamente, a fines del XIX, por "ciencia del lenguaje" hay que entender el paradigma dominante de los neogramáticos (respecto de los cuales, sin embargo, Lenz mantuvo cierta distancia crítica que posibilitó su acercamiento a Hugo Schuchardt; $c f$. Sousa y Mücke 2016). Estos se diferenciaban frente al comparativismo histórico temprano al declarar 
que el principal objetivo de la ciencia del lenguaje era entender el cambio lingüístico en cuanto proceso natural y que este se podía conocer de la mejor forma a través del estudio del habla viva en boca de los pueblos actuales, distanciándose así del enfoque "filológico" anterior y emancipando su objeto de estudio como fin en sí mismo. (Ennis 2016: 125)

Desde sus primeros años en Chile, Lenz había manifestado "la seguridad de que el estudio del español de América va a dar de sí enseñanzas sumamente provechosas" a los romanistas europeos, "por las numerosas analogías que existen entre la expansión románica en Europa y la expansión española en el Nuevo Mundo", y porque en América "la españolización data de pocos siglos y las lenguas indígenas no se han extinguido aún en la mayor parte de los países donde se hablaban" (Lenz [1892-1893] 1940: 91). Específicamente, su país de acogida era de especial interés para la ciencia europea porque "si en alguna parte de America había y hay las condiciones exigidas para la formación de una nueva lengua, debe ser en Chile" (Lenz [1893] 1940: 220). Se trataba, entonces, de una inmejorable oportunidad para que Lenz se hiciera un nombre: se había encontrado en Chile con un magnífico laboratorio etnográfico (siguiendo la denominación afortunada de Pavez 2015) para estudiar el cambio lingüístico in vivo, lo cual lo podía situar en la primera línea de la ciencia del lenguaje de la época, asegurando así su posición en el espacio público chileno. (Ennis 2016: 126)

El laboratorio en cuestión estaba habitado fundamentalmente por los guasos ("el estrato último de la pronunciación rural, cuya pronunciación y vocabulario son los que más rasgos indígenas ofrecen"; Lenz [1892-1893] 1940: 92) y los rotos ("la clase ínfima" urbana, "el proletariado"; ibid.). Igual como en el caso del latín vulgar, "no es la lengua clásica de las capas sociales superiores, sino la lengua común del pueblo la que proporciona las bases para la nueva evolución" (Lenz [1893] 1940: 211-212). La condición analfabeta de ambos grupos significaba que "no hay, por tanto, estorbos en la evolución fonética" (Lenz [1892-1893] 1940: 93). El punto clave es que este "pueblo", los guasos y los rotos, son, para Lenz, fundamentalmente mapuches castellanizados: "el núcleo principal de la población baja está constituido casi exclusivamente por indios que han olvidado su lengua e introducido algún cambio en su género de vida" (Lenz [1893] 1940: 227).

Este es el marco general en el que hay que entender el sentido global del Diccionario etimológico de Lenz: su propósito es "consolidar lexicográficamente su tesis sobre los sustratos indígenas en el español de Chile" (Pavez 2015: 118) que prometía convertirse en una contribución de peso a la romanística y a la teoría del cambio lingüístico. Su condición culminante en el marco de este proyecto intelectual también es referido por Ferreccio, quien considera esta obra, publicada en su parte inicial 15 años 
tras la llegada de Lenz al país, "la consumación de un espigueo iniciado muy a los comienzos de su ministerio chileno" (1979: 7). Como observa el propio Ferreccio, la misma página donde va el título de la obra lleva un encabezado que inscribe al Diccionario como la "primera parte" de un estudio mayor inconcluso titulado Los elementos indios del castellano de Chile. Estudio lingüístico y etnológico. Del largo arco de trabajo que representaría esta obra también es síntoma la demora en su publicación final: iniciada la recolección de materiales prácticamente desde que Lenz llegó a Chile, la primera entrega se empezó a imprimir en 1904, pero este no empezó a circular sino hasta 1905, y la segunda parte, aunque estaba prevista para 1906, terminó apareciendo por comienzos de 1910. (Ferreccio 1979: 22)

Cabe destacar que el propio Lenz no concibió la publicación de 1910 como el cierre del proyecto, ni siquiera en su parte lexicológica. El léxico indígena del castellano chileno siguió siendo objeto de atención para Lenz, años después de haberse publicado el Diccionario etimológico, como demuestra el dato de que, entre las conferencias que dictó en el Centro de Estudios Históricos en Madrid en 1922, hubo una (dictada el 4 de febrero) dedicada a "Influencias indígenas en la formación del español en América. II. El diccionario" (ABC, viernes 17/01/1922, pág. 16). Asimismo, en la conferencia que dictó en el Salón de Honor de la Universidad de Chile el 23 de noviembre de 1927, sobre Problemas del diccionario castellano en América, afirmaba: "en 1910 concluí provisoriamente mi Diccionario etimológico de las voces chilenas derivadas de lenguas indígenas americanas" (Lenz 1927: 9). Finalmente, a esto debe añadirse la mención a una segunda edición en preparación, en carta a Augusto Malaret de 1928: "Tengo en mi ejemplar del DE una infinidad de notas al margen: pero me parece muy dudoso si alcanzaré alguna vez una segunda edición" (carta de Lenz a Malaret, 30/10/1928). Precisamente en esas notas, conservadas en al menos tres ejemplares de propiedad de Lenz, se basó Mario Ferreccio para sus intervenciones al texto original que dieron forma a su edición crítica de 1979.

\subsection{La RECEPCIÓN DEL DiCCIONARIO}

Como argumenta Chen (2019), basándose en Fairclough (1992) y Van Dijk (2003), para apreciar correctamente el efecto ideológico de un discurso lexicográfico es necesario tener en cuenta "how texts are interpreted and received, and what social effects they have" (Chen 2019: 376). Los trabajos de Rojas y Avilés $(2012,2015)$ muestran, precisamente para el caso de la tradición lexicográfica chilena, que el efecto glotopolítico de los diccionarios 
no puede comprenderse cabalmente si no se tiene en cuenta su recepción por parte de la comunidad a la que están dirigidos, que en buena medida corresponde a los propios integrantes del campo científico o intelectual.

Para el caso del Diccionario de Lenz, contamos con las evidencias aportadas por las reseñas, en su gran mayoría elogiosas, que se publicaron tanto en Chile como en el extranjero. Aparte de las reseñas positivas mencionadas por Pavez (2015: 120), a saber: las del romanista de Graz, Hugo Schuchardt, y las de los chilenos Diego Barros Arana y Tomás Guevara (a las que hay que sumar la crítica negativa de Román), en nuestro estudio nos interesa considerar una muestra adicional de reseñas que nos parecen relevantes por mostrar de modo más amplio la recepción que tuvo el Diccionario etimológico en los círculos especializados tanto de Europa como de América Latina.

El propio Lenz conservó en su archivo personal una colección de estas reseñas (un par de las cuales reprodujo en las versiones impresas de su Diccionario $^{5}$ ), en forma de recortes o de transcripciones/traducciones hechas a mano, depositadas hoy en el Fondo Lenz de la Universidad Metropolitana de Ciencias de la Educación, en Santiago de Chile. Cabe recordar que Lenz constituyó su prestigio, autoridad y posición en el medio chileno al menos en parte mediante el resalte de la recepción positiva de que su obra gozaba en Europa, en el campo científico dedicado al estudio del lenguaje,como muestra el que "desde muy temprano se afana en mantener el vínculo y asegurarse la recepción y el diálogo con sus colegas europeos" (Ennis 2016: 130), por ejemplo, mediante la puesta en circulación de sus hallazgos primero en lengua alemana y en revistas de primera línea de su especialidad, y solo después en castellano y en revistas nacionales (como sucede con "Chilenische Studien" de 1892-1893, publicados primero en la revista Phonetische Studien, editada por W. Vietor). A esto habría que sumar la densísima red de correspondencia que articuló tanto hacia el extranjero como hacia las regiones de Chile ( $c f$. Velleman 2008 y Pavez 2015: 96 y ss.), la que, además de mecanismo de levantamiento de información, muchas veces fue el mecanismo para establecer relaciones públicas.

\footnotetext{
Escudero (1963: 481) menciona en su inventario de "Algunas fuentes consultables”, que tanto la reseña de Zauner como la de Cejador fueron reproducidas en un anexo del Diccionario, en las páginas 931-932 y 934-938, respectivamente. Debe tratarse del primero de los anexos, suprimidos por Ferreccio en la reedición de 1979. Véase al respecto lo que apuntamos más adelante sobre el anexo 2, también suprimido, correspondiente a la respuesta de Lenz a la crítica de Román publicada en la Revista Católica.
} 
Una de las reseñas que mayor importancia parecen haber tenido para el propio Lenz es la que hizo el connotado romanista Adolf Zauner, de la Universidad de Viena, publicada en 1908 en la revista alemana Literaturblatt für germanische und romanistische Philologie. Lenz remite al lector a esta reseña, a propósito de las críticas que al Diccionario etimológico había hecho Manuel A. Román ( $c f$. Lenz s/f.: 5, nota 13). Zauner fue discípulo de una de las figuras dominantes de la romanística de fines del siglo XIX, Wilhelm Meyer-Lübke y autor de un manual de lingüística románica (Romanische Sprachwissenschaft, publicado en Leipzig en el 1900, y en el cual el trabajo de Lenz es mencionado como la única caracterización científicamente solvente de una variedad del castellano) ampliamente conocido en su época. Es decir, fue una figura central en su campo científico, de modo que su opinión positiva de la obra de Lenz tenía un alto valor en el mercado del prestigio académico. Lenz guardó en su archivo personal una transcripción íntegra de la reseña de Zauner, que se extiende por 5 páginas manuscritas, así como un resumen de una página en castellano en que Lenz seleccionó los pasajes más relevantes. Entre estos, reveladores de qué le interesaba resaltar a Lenz, se encuentran: "En la introducción el autor espone los principios que lo han guiado en la elaboración del diccionario. Apenas es necesario decir que son absolutamente los principios de la ciencia moderna", y "El Diccionario de Lenz es una obra profunda i concienzuda, por cuya aparicion debemos felicitarnos i que es indispensable para todos los que se ocupan en el estudio del castellano de América". Asimismo, Lenz pone en un paréntesis que la reseña incluye "un análisis detallado de la obra en que se hace resaltar particularmente la importancia de los términos que se refieren al lenguaje de niños i a la esfera sexual [...], términos por los cuales el autor ha sido duramente criticado por un anónimo de la Revista Católica, 4 de nov. 1905”. Este anónimo es Manuel Antonio Román, y es importante notar cómo en esta traducción/resumen se vislumbra la intención de Lenz de usar los elogios de Zauner como escudo contra la crítica de Román, que comentaremos más adelante.

Otra reseña conservada por Lenz es la que el español Aurelio M. Espinosa, profesor de la Universidad de Stanford y primer editor de Hispania, publicó en 1910 en la Revue de Dialectologie Romane, órgano oficial de la Société Internationale de Dialectologie Romane, dirigido entre otros, por R. Menéndez Pidal, J. Leite de Vasconcellos y M. G. Bartoli, es decir, por lo más selecto de la romanística europea no germánica. En las cartas de Espinosa a Lenz editadas por Velleman (2008) se puede ver que el propio Lenz envió una copia de su Diccionario etimológico al español, pero que este le hizo saber que esperaría hasta recibir la segunda entrega para publicar una reseña. En septiembre de 1910 este le comunica: "Estoy preparando una reseña 
concienzuda de su trabajo que espero le servirá de 'tapabocas' a los rústicos" (cit. en Velleman 2008: 23); con lo último se refiere a la crítica de Román. En su reseña, Espinosa destaca que "se puede afirmar con entera seguridad que en el estudio crítico y verdaderamente científico del Castellano de América, solo el Dr. Lenz y el insigne autor de las Apuntaciones [...] se cuentan entre las [sic] filólogos de la ciencia contemporánea" (Espinosa 1910: 420), y que en particular en el Diccionario etimológico "ha hecho aún más que lo que se podía esperar de un solo individuo" (ibid.). Otras apreciaciones de Espinosa son: "La Obra de Lenz es, en nuestra opinión el trabajo más importante que hasta ahora se ha publicado en el terreno de que se trata" (Espinosa 1910: 421); "Este método [seguir la máxima de que la más grande autoridad en el idioma español es el español mismo], absolutamente científico, es digno de toda alabanza" (ibid.); "El estudio del diccionario es estudio etnológico y lingüístico de profunda erudición". (Espinosa 1910: 422)

El filólogo y lexicógrafo histórico-comparatista español Julio Cejador, en su "Bibliografía sobre el Castellano de América" publicada en La España Moderna en 1907, dedica algunos breves comentarios al Diccionario de Lenz (copiados a mano por Lenz), en el marco de su examen de obras "sobre palabras de origen indíjena" (Cejador 1907: 11). Cejador menciona primero los Estudios etimolójicos de las palabras de origen indígena usadas en el lenguaje vulgar que se habla en Chile (1902) de Alejandro Cañas Pinochet, y añade: "Pero este trabajo es mui reducido e incompleto" (Cejador 1907: 11) en comparación con el Diccionario de Lenz, "primer i único en su jénero" (Cejador 1907: 12). Califica a su autor de "verdadero lingüista que está al tanto de cuanto se publica en Europa i sigue los métodos de la ciencia moderna" (Cejador 1907: 11-12). Entre las virtudes metodológicas de la obra están el que "cita los autores donde se halla cada voz, aunque por su mayor parte las ha ido él mismo a buscar entre las jentes del pueblo" (Cejador 1907: 12), es decir, el texto tiene un sustento empírico que cumple con los requisitos más exigentes del positivismo cientificista. Por esta razón, Cejador confía totalmente en la veracidad de las etimologías proporcionadas por Lenz, lo cual lo lleva a instaurarlo como autoridad primera para ser considerada por la RAE cuando "trate de incluir en su Diccionario los vocablos americanos de orijen indio". (Cejador 1907: 13)

El lingüista y filólogo cubano Juan Miguel Dihigo (creador del primer laboratorio de fonética experimental en la Universidad de La Habana, lo cual lo pone claramente en afinidad de intereses académicos con Lenz), en su reseña publicada en la Revista de la Facultad de Letras y Ciencias de la Universidad de La Habana, reitera algunas de las razones que justifican en otras reseñas la apreciación positiva del Diccionario de Lenz, tales como la paciencia y el escrúpulo, o la sofisticación empírica ("ha bajado al pueblo 
para obtener las voces que le son propias [...] Allí y solo allí es donde hay que ir para hallar el material necesario mantenido siempre puro"; Dihigo s/f: 96). Añade, por otra parte, que "no es la crítica del Dr. Lenz la que se echa de ver en los pueblos de raza latina, violenta y desagradable; su crítica es templada, imparcial, desapasionada, tendente á dar á conocer la razón de la diferencia en el modo de apreciar los hechos, inclinada siempre á poner bien de manifiesto la verdad de los mismos" (Dihigo s/f: 97). También muestra la resonancia que ya habían tenido en el ámbito especializado las reseñas elogiosas de los especialistas, especialmente de Alemania, las que atendían a su importancia para los intereses de la lingüística histórica:

Por eso es que la prensa acogió con aplauso oportunamente la benedictina labor del Dr. Lenz; por eso es que ha sabido significar cuánto aprecia el mérito de la misma, y por eso los profesionales -Cejador, Morf, Lehmann, Zauhner [sic, por Zauner]- al aquilatar lo que otros en grado inferior han sabido juzgar dentro de la relatividad de sus conocimientos, han aplaudido con ardor la publicación de una obra que ha de prestar utilidad grande á la importante causa de la pesquisa lingüística. (Dihigo s/f: 96) Ya la crítica alemana ha dado á conocer el mérito de este Diccionario y por boca del Profesor Tauner [sic, por Zauner], hizo "consistir el valor principal de la obra y su utilidad más grande, en el hecho de que en Chile puede observarse en sus comienzos un fenómeno idéntico al que durante la época de romanización se verificó en Europa [...]”. (Dihigo s/f: 96-97)

No solo entre filólogos y lingüistas tuvo resonancia la obra de Lenz. En la reseña del famoso etnólogo francés Paul Rivet, publicada en París en 1911 en el Journal de la Société des Américanistes, este hace ver que "L'intérêt de cette oeuvre est considérable pour tous ceux qui si'intéressent aux êtudes américaines" (Rivet 1911: 337). Frente a la tradición normativista de la lexicografía americana del siglo XIX, Rivet destaca que Lenz se aparta de esa tradición "pédantesque" (ibid.) al intentar componer "un dictionnaire complet de tous les provincialismes dont s'est enrichie la langue espagnole depuis la conquête" (ibid.). Igual que Cejador, Rivet considera un aporte de Lenz el poner en pie de igualdad los neologismos americanos frente a los europeos, lo cual llevará a "leur consécration définitive" (ibid), con lo cual se refiere a su inclusión en el Diccionario de la RAE.

En el ámbito nacional, además de los ya mencionados Tomás Guevara y Barros Arana, Omar Emeth (seudónimo del sacerdote francés y crítico literario avecindado en Chile Emilio Vaisse, coautor de un diccionario de cunza, con Aníbal Echeverría y Reyes y Félix Hoyos) dedicó palabras elogiosas al Diccionario de Lenz en El Mercurio (Santiago) del domingo 18/09/1910, en una columna dedicada a "El nombre de Chile y otros nombres". En este texto, destinado al lector de prensa cultural, es decir, que 
pone al Diccionario en circulación más allá de los círculos estrictamente especializados, declara que "la lectura del Diccionario Etimológico del doctor Lenz ha sido para mí del mayor provecho y de la más perfecta amenidad. Desde luego creo difícil que exista libro más rico en explicaciones acerca de la etimología de muchos vocablos que, a pesar de su origen indio, tienen hoy derecho de ciudadanía en el idioma español" (Emeth 1910). Nuevamente se hacen resaltar el método empírico y el tratamiento y presentación minucioso y sistemático de la información recogida, cuestiones que el propio Emeth considera inusitadas en el medio académico nacional:

Es obra magna, digna de benedictino. Para escribirla ha desplegado el insigne filólogo una energía, una paciencia y una inteligencia que hoy en día distan mucho de ser comunes, al menos en el mundo en que vivimos. La preparación de los materiales le ha exigido largos viajes al través de las provincias australes, investigaciones prolijas y un sinnúmero de preguntas y respuestas dirigidas á gentes tan prontas para proporcionar datos filológicos como lo son las zarzas para dar uvas, ó manzanas. Quien haya alguna vez interrogado á indios ó á campesinos acerca del significado de un vocablo, comprenderá el esfuerzo y diré el cuasi-heroísmo exigido por la tarea de escribir un diccionario como el presente. Agréguese a esto la lectura, anotación, copia de datos sacados de centenares de libros, revistas, periódicos y cartas; la crítica minuciosa de todos éstos; la clasificación y redacción de apuntes que llenan 936 páginas de impresión en extremo compacta. Todo esto permite vislumbrar el trabajo y medir el esfuerzo del doctor Lenz, á quien no trepido en atribuir el "robur et aes triplex" de que habla Horacio. Ahí tenemos el fruto de varios años de estudio é investigaciones que honran sobremanera á quien las emprendió y á la Universidad de Chile que las publicó en sus Anales. (Emeth 1910)

A pesar de esto, la crítica nacional que mayor resonancia pareció conseguir fue la que hizo de forma anónima el sacerdote chileno Manuel Antonio Román, hispanista conservador furibundo y autor de un Diccionario de chilenismos en la tradición normativista de fines del siglo XIX ( $c f$. Norambuena 2016). La reseña de Román fue publicada en la Revista Católica en 1905, y motivó que Lenz añadiera en el Suplemento III de su Diccionario (incluido en la segunda entrega, de 1910) un comentario crítico del Diccionario de chilenismos de Román, en la línea de las que había incluido en la bibliografía de la primera entrega. Ya en esta versión, Lenz aprovecha de comentar también las críticas de Román aparecidas en la Revista Católica, pero la respuesta que podríamos considerar definitiva por parte de Lenz quedó plasmada en el "Anexo segundo al Diccionario Etimolójico de Voces Chilenas derivadas de lenguas indígenas americanas", 
impreso como "publicación privada del autor", de 8 páginas de extensión, que Ferreccio decidió no incluir en su edición del Diccionario, quizá por haber estado "añadido a muy contados ejemplares" (Ferreccio 1979: 22), pero sobre todo por el hecho de que el propio Lenz, en sus ejemplares de trabajo, los "coronó atinadamente con un mayúsculo NO manuscrito: son piezas de polémica y autodefensa implícita, que no aportan nada al diccionario" (Ferreccio 1979: 24). Puede que no sirva para conocer etimologías, pero sin duda que el anexo segundo sirve para conocer mejor las razones de la recepción negativa del Diccionario etimológico entre algunos sectores de la intelectualidad chilena.

En la versión de la respuesta de Lenz publicada en el Suplemento III (analizada por Pavez 2015: 130-131), el alemán hace ver que el autor anónimo de la reseña de la Revista Católica era Román, y hace ver que varias etimologías dadas por el sacerdote probablemente las sacó del Diccionario etimológico sin reconocer la fuente. Asimismo, reproduce un párrafo extenso de esa reseña en que Román afirma que una obra como la de Lenz "hace un verdadero i funestísimo mal al pais: corrompe la enseñanza del castellano, hace perder todo criterio lingüístico" (cit. en Lenz [1905-1910] 1979: 912), pues no sigue ningún criterio, y peor aún, los desprecia.

En la versión impresa como “Anexo segundo...”, Lenz reproduce amplios segmentos de la reseña de Román, las que va comentando en notas a pie de página. Se evidencia, en este diálogo, una divergencia radical en la manera de entender el estudio del lenguaje:

Por esta razón hemos creído y creemos que todo el que se dedique al estudio del lenguaje tiene la noble misión de encauzarlo en las leyes de la gramática, desbastándolo, puliéndolo y limpiándolo según las exigencias de la civilización y de la simple educación. Si así no fuera, la ciencia del lenguaje no sería ciencia sino mero inventario de palabras, desde la que estropea con su mala pronunciación el último patán, hasta las que profieren con cínica desvergüenza el borracho en la taberna y el frecuentador de burdeles. (Román, cit. en Lenz s/f.: 1-2)

Esta definición del estudio del lenguaje (digamos de la lingüística) es tan correcta como si se dijera que la botánica tiene por objeto producir hermosas flores, peras dulces y papas grandes. La confusion entre retórica y lingüística es a lo menos falta tan grave como si se declarara que horticultura y botánica son una misma cosa. La mala pronunciación del último patan puede tener para la lingüística el mismo interés que un cultivo de bacilos de la peste bubónica para la biología y la medicina. (Lenz s/f.: 2, nota 1) 
Un punto específico en que Román repara con saña es en el lugar que Lenz le estaba otorgando al estudio del habla del pueblo. Lenz responde resaltando que esto es un aporte a la nación, más que algo criticable:

Hasta ahora todos habíamos creido que la enseñanza de la gramática era para hablar y escribir correctamente, como la gente educada; pero ahora el Dr. Lenz nos dice que estábamos profundamente equivocados y que la gramática, por lo menos en Chile, es para hablar y escribir 'la lengua huasa'. (Román, cit. en Lenz, s/f.: 4)

Verdad es que he sido el primero que ha dado a conocer a los hombres de ciencia las particularidades del lenguaje vulgar de Chile. Los romanistas europeos conocen mis Chilenische Studien (en Phonetische Studien ed. Vietor, tomo V i VI). En castellano hasta hoy no he publicado casi nada sobre esta materia. En cambio he enseñado a algunos jóvenes chilenos que no necesitan avergonzarse de su lenguaje vulgar, que el cultivo poético del dialecto patrio es un título de gloria entre las naciones mas adelantadas del mundo. Fue una gran satisfacción para mí que poetas de talento como el joven Antonio Orrego Barrios, para solo nombrar al primero, me dedicaran sus primeras poesías escritas en lenguaje vulgar chileno. Pero nunca he fomentado entre mis alumnos la tendencia de mezclar el lenguaje vulgar con la lengua literaria castellana, aunque estoi léjos de recomendar el supuesto "casticismo académico" por el cual aboga el señor Román. Creo no hacer mal servicio a Chile si continúo, en la Sociedad de Folklore chileno recien fundada por mí, enseñando a los chilenos el estudio del alma popular chilena en todas sus manifestaciones. (Lenz s/f: 4-5, nota 11)

Román concluye su reseña conminando a Lenz a abandonar su proyecto académico, específicamente en lo relativo al habla del pueblo y a la etimología indígena (respecto de lo cual Román acusa a Lenz de severas deficiencias), y Lenz por su parte pone punto final aclarando por qué se ha ocupado con tanto esfuerzo de la reseña de Román:

Concrétese, cuanto mas, a la fonética del castellano, que es su especialidad, pero no venga a echarnos a perder lo poco que nos queda de la lengua que tanto nos enseñó, corrigió i purificó el filólogo verdadero i consumado gramático don Andres Bello. (Román, cit. en Lenz, s/f.: 8)

No habría reproducido esta critica de la Revista Católica, que no tiene ningún valor científico, si no tuviera yo interés en mostrar a mis amigos i al público científico en general, a qué ataques se encuentra todavía espuesto el investigador científico que trabaja por el adelanto de la enseñanza pública, de parte de cierta jente que suele cubrir con un 
disfraz venerable el odio al extranjero i al progreso de la ciencia i de la instrucción del pueblo. (Lenz s/f: 8, nota 28)

Otra zona del archivo lenziano donde se manifiesta la legitimación que Lenz quiere articular para su obra a partir de la recepción en el medio especializado es la correspondencia recibida a propósito del Diccionario, que da cuenta al mismo tiempo de cómo Lenz movilizó intencionalmente una reacción por parte de un grupo selecto de intelectuales, al enviarles él mismo ejemplares. Entre estos intelectuales se contaban el antropólogo Frederick Starr (Chicago), el político y lingüista John D. Prince (New Jersey), el político y escritor Ricardo Rojas (Buenos Aires), el periodista y lexicógrafo Vicente Rossi (Córdoba), Fr. Miguel Sanz de Villalómez (Cajamarca), el fonetista portugués Aniceto dos Reis Goncalvez Vianna (Lisboa) y el lexicógrafo español Miguel de Toro y Gisbert (París). Entre los comentarios elogiosos recibidos y conservados por Lenz destacamos aquellos que abundan en calificativos para el Diccionario:

This work is a valuable contribution to the linguistic literature of South America, and bears testimony to your enterprise and to the scientific awakening of the more advanced countries of South America. (Carta de William Henry Holmes, antropólogo del Smithsonian Institution, a Lenz, 29/11/1905)

Muchas gracias por su Diccionario Etimolójico I, obra grandiosa i brilante, que manifiesta un trabajo enorme, gran sabiduria i un tino filolójico delicado i agudo. (Carta de Johan Storm, lingüista y filólogo especialista en inglés y lenguas romances de la Universidad de Kristiania [Oslo], a Lenz, traducida por Lenz, 17/12/1905)

Ahora solamente he encontrado el tiempo para revisar la primera entrega de su Diccionario Etimolójico i no quiero dejar de manifestarle mi sincera admiracion i satisfacción. Todo el mundo científico de los romanistas le debe las gracias a Ud i en cuanto lo vea, todos lo reconocen sin limitación alguna i con entusiasmo. (Carta de Carolina Michaelis de Vasconcellos, "conocida romanista alemana-portuguesa", a Lenz, traducida por Lenz, 28/04/1906)

Finalmente, parece haber tenido una especial importancia para Lenz el reconocimiento que significó para su Diccionario la decisión de la Facultad de Humanidades de la Universidad de Chile, aprobada por el Consejo universitario y oficiada al Ministerio de Instrucción Pública, de "Fijar en mil pesos anuales la recompensa que corresponde al Dr. don Rodolfo Lenz por su libro titulado 'Diccionario de Voces Chilenas'”, comunicada en documento firmado por el rector Domingo Amunátegui el 10/08/1916. 
De todo este conjunto de reseñas y cartas, tal como quedaron archivadas bajo la curatoría del propio Lenz, se puede concluir que una característica sobresaliente de la obra, a ojos del público especializado, era el grado en que satisfacía las exigencias del positivismo cientificista, y su ajuste a los dictados epistemológicos y metodológicos de las modernas ciencias del lenguaje, así como en general de las ciencias antropológicas. La legitimidad del Diccionario, por lo mismo, se basaba principalmente para Lenz en la recepción positiva de esta obra, en la metrópoli europea de estas disciplinas, a partir de ese conjunto de características, tal como refleja de forma prototípica la reseña de A. Zauner, que incluso otros críticos reconocieron como la consagración definitiva del Diccionario.

\section{EL DICCIONARIO ETIMOLÓGICO EN EL MARCO DE LA SOCIEDAD DE FOLKLORE CHILENO}

Establecido el rol del Diccionario etimológico en la maquinaria de la lingüística colonial europea, habrá que tener en cuenta que su condición de diccionario etimológico (esto es, cuyo propósito e informar sobre el origen de las palabras) justamente responde a su función de servir a una disciplina interesada fundamentalmente por el cambio lingüístico y la historia de las lenguas, y que había hallado en territorio chileno un excelente laboratorio para observar su funcionamiento. Aunque en este caso se puede observar una función glotopolítica "global" o "exterior" del diccionario, de su misma naturaleza etimológica brota un sentido glotopolítico nacional/local, relacionado con la "transposability of linguistic images of the past to political and cultural projects in the present" (Errington 2008: 89), y que creemos puede apreciarse con mayor claridad resaltando una arista habitualmente soslayada del contexto de producción de la obra y a cuyo conocimiento pretendemos contribuir de forma novedosa en este artículo: su inscripción en el proyecto intelectual de la Sociedad de Folklore Chileno (en adelante, SFCh), fundada por Lenz en 1909.

La fundación de la SFCh en 1909, por iniciativa de Rodolfo Lenz, debe ser comprendida en el marco del predominio del positivismo cientificista que servía como eje para la modernización del Estado-nación. Hay que tener en cuenta que en Chile el positivismo "alcanza su cumbre entre 1890 y 1916, cuando por medio de la analogía entre sociedad y naturaleza, la noción de raza adquiere relevancia" (Concha Ferreccio 2015: 21). Las teorías racionales como las de Herbert Spencer o Gustave Le Bon sirvieron a las 
intelectualidades latinoamericanas para pensar el problema de la nación y la identidad en términos que prometían la seguridad de la conclusión científica. (Subercaseaux 2007)

La creación de la SFCh es un caso ejemplar de aquellas institucionalizaciones de la actividad científica que fueron comunes desde la segunda mitad del siglo XIX en Latinoamérica, y en particular guarda relación con la institucionalización de la antropología en Europa y Estados Unidos a mediados de ese siglo, "una disciplina ambiciosa y [de] voluntad aglutinadora muy fuerte, lo que hacía que bajo su capa nominal cupiera casi todo" (Bustamante 2014: 167). Por lo menos hasta las primeras décadas del siglo XX, hubo en las ciencias antropológicas una aspiración de "integralidad" respecto de la investigación acerca de las diversas facetas del ser humano. Esta idea inicial luego derivó en el estudio particular o comparativo de pueblos "indígenas" o "salvajes", con lo cual se delimitó un objeto de estudio propio: "la alteridad radical u otredad indígena". (Mora y Vásquez 2018: 24)

Fue esta última perspectiva la que cobró mayor fuerza en el contexto chileno, donde "las ciencias antropológicas eran entendidas como el campo que agrupaba a un conjunto de áreas o ramas que se ocupaban del estudio de 'los pueblos naturales o la baja civilización'" (Mora y Vásquez 2018: 28). Mora (2016) identifica en la producción bibliográfica antropológica chilena de estos años la presencia de cinco grandes ramas de la disciplina: arqueología y prehistoria, etnología y etnografía, antropología física, folklore y lingüística. En el caso del folklore, "integra la recopilación de relatos, cuentos, canciones y objetos en población indígena, sectores populares y rurales", y la producción lingüística "considera glosarios y estudios etimológicos, traducciones y gramáticas de la lengua de los pueblos 'aborígenes"'. (Mora y Vásquez 2018: 31)

A partir de este marco epistemológico, el 18 de julio de 1909 Rodolfo Lenz lidera la fundación de la SFCh, que también integraron como miembros fundadores Enrique Blanchard-Chessi, Agustín Cannobbio, Eliodoro Flores, Ricardo Latcham, Ramón Laval, Antonio Orrego Barros, Julio Vicuña Cifuentes y Francisco Zapata Lillo (Dannemann 2010: 58). En 1913, la SFCh se convirtió en la sección de Folklore de la Sociedad Chilena de Historia y Geografía (fundada en 1911) y estuvo activa hasta 1922, luego de lo cual sufrió una prolongada pausa, hasta 1982.

Los estatutos incluidos en el Programa de la SFCh (Lenz 1909) establecen las funciones de la sociedad: "fomentar el estudio del folklore chileno (F. Ch.) i facilitar la publicación de toda especie de trabajos referentes a esta ciencia". Es de destacar que se refiera al estudio del folklore como una "ciencia", pues de esta manera activa de inmediato el imaginario cientificista que viene a 
legitimar la actividad en un contexto de hegemonía del positivismo. En suma, se trata de una institución de fomento de la ciencia, con lo cual puede aspirar a insertarse exitosamente en la maquinaria estatal de producción de conocimientos y consecuentemente conseguir recursos y prestigio para sus tareas. En el mismo sentido hay que interpretar su vínculo estrecho con el Instituto Pedagógico, gracias a lo cual pudo representarse como una sociedad al servicio del Estado.

Otros artículos de los estatutos indican la estructura administrativa de la sociedad (encabezada por un directorio), los tipos de miembros (activos, adherentes y corresponsales) y los mecanismos de ingreso. Interesa destacar acá que los miembros activos, de no residir en Santiago, tendrían la condición de miembros correspondientes. Esta categoría es importante porque permite entrever la intención de establecer una red de "satélites" regionales que permitan el conocimiento del folklore chileno en su variación geográfica, cuestión sobre todo importante por la todavía reciente expansión territorial del Estado chileno debida a la Guerra del Pacífico (en lo relativo a la zona norte) y a la Ocupación de la Araucanía (en lo que concierne al sur).

El Programa, junto con demostrar la centralidad de Lenz en la sociedad (por ser su único autor), permite conocer las líneas generales de la naturaleza y tareas que se autoatribuía la SFCh, así como el lugar que ocuparía entre estas el estudio del lenguaje. Sirve, entonces, como una hoja de ruta con ayuda de la cual luego podrá entenderse de mejor manera el sentido global de cada una de las obras lingüísticas publicadas por los miembros de la SFCh, entre ellas el Diccionario etimológico de Lenz. Cabe precisar, en primer lugar, que a pesar de que el comienzo de su elaboración y publicación antecede por varios años a la creación de la Sociedad, su fecha de compleción, 1910, permite igualmente adscribirla a la producción asociada a este grupo de investigadores. Por otra parte, el propio autor lo incluyó entre los productos planificados en el marco de los intereses declarados en el Programa de la SFCh. En este sentido, siendo su concepción y publicación parcial anterior a la fundación de la SFCh, habría que pensar que el Diccionario etimológico es más bien objeto de apropiación por el proyecto intelectual de esta institución.

El Programa incluye dos breves textos de carácter teórico. Primero, "Etnolojía i folklore" de Lenz, que según se indica en nota pie de página es una síntesis del "discurso de inauguración de la sesión de $10^{\circ}$ de Agosto i, en lo esencial, un estracto del libro del Dr. R. F. Kaindl, Die Volkskunde, ihre Bedeutung, ihre Ziele und ihre Methode. Leipzig 1903". Segundo, un "Ensayo de programa para los estudios de folklore chileno", que es precisamente el texto preparatorio que Lenz había escrito en 1905 y que había presentado a la Facultad de Humanidades de la Universidad de Chile el 9 de julio de ese año. Finalmente, hay un texto que cumple una función 
principalmente metodológica: "Fonetica chilena i reglas para la trascripcion de documentos". El lugar de los estudios del lenguaje en esta sociedad se puede apreciar en estas tres últimas secciones, pero principalmente en "Etnolojía i folkore" y el "Ensayo de programa...".

Según "Etnolojía i folklore", el folklore forma parte de la etnología, la que "investiga las leyes de la formación de la humanidad con el fin de presentar un cuadro de la vida síquica" (Lenz 1909: 5), poniendo énfasis en "lo que piensan los pueblos como colectividad" (ibid.), es decir, la idea étnica. Si bien todos los seres humanos tienen en lo fundamental y en potencia las mismas cualidades físicas y síquicas, distintos grupos humanos se encuentran en distintas etapas de "desenvolvimiento" o desarrollo, lo que abre la puerta a la distinción entre pueblos "naturales, i de baja civilización" o "razas primitivas", y pueblos desarrollados o civilizados o "de alta cultura" (ibid.). El interés de estudiar a los primeros es que permitirían conocer cómo fueron los segundos "en la época que se pierde en las tinieblas de la prehistoria" $(i b i d$.$) . Lo recién señalado inserta claramente los estudios$ del folklore en una matriz evolucionista (pueblos atrasados / pueblos adelantados) y los dibuja como posible contribuyente a insumos para asegurar el ideal del progreso, junto con ubicar al folklore en el marco de lo que Wilhelm Wundt (figura por lo demás influyente en Lenz, sobre todo en sus estudios de gramática; $c f$. Gómez Asencio 2016) llamó sicología de los pueblos. Una de las premisas fundamentales de Wundt era que diversas manifestaciones de la cultura humana, tales como el lenguaje, los mitos o la religión, son reflejo de los procesos mentales más altos, de modo que habrá que entender que para los miembros de la SFCh en general el estudio del lenguaje y las manifestaciones culturales asociadas a este permiten acercarse a la mentalidad del pueblo chileno y mapuche.

Otro punto importante es que la etnología "no puede existir sin las demas ciencias; tiene que aprovecharse de todas ellas" (Lenz 1909: 6). He aquí la perspectiva integral y aglutinadora de las ciencias antropológicas. Sin embargo, algunas disciplinas tienen una afinidad más estrecha con la etnología, entre ellas el folklore. Esta es "aquella rama de la ciencia del hombre que busca la mayor parte de los materiales que se necesitan para la aplicacion del método inductivo i comparado de la etnolojia" (Lenz 1909: 8); al mismo tiempo, designa "todas las variadas manifestaciones del alma popular i todas las formas características de la vida del pueblo" (Lenz 1909: 9). Estas "manifestaciones" y "formas" que para la disciplina son "materiales" corresponden a "los mitos i todas las manifestaciones de las creencias populares, las leyendas, las consejas, los cuentos, cantos i proverbios, las supersticiones i costumbres" (Lenz 1909: 8). Se entiende entonces, que el folklore, en la primera acepción, cumple la misión de 
recoger las bases empíricas a partir de las cuales la etnología podrá levantar inductivamente una filosofía fundamentada sólidamente en el pensamiento de todos o la mayoría de las colectividades humanas. Aún más, en una cita que Lenz reproduce literalmente (pero traducida, por supuesto) del libro de Kaindl, aparece destacada la idea de que el folklore tiene la misión de salvaguardar los vestigios de etapas antiguas de la humanidad que todavía se conservan en algunas culturas primitivas existentes hoy, y que se ven amenazadas de desaparecer por el avance tecnológico y civilizatorio: " $\mathrm{Hai}$ incendio, devastador incendio en el mundo etnolójico', esclama con razon Bastian. Pues, urje salvar i guardar los preciosos restos". (Lenz 1909: 11)

Lenz constata que "la ciencia del folklore es mui moderna" (Lenz 1909: 9), y que si bien en el siglo XIX los europeos dieron importantes pasos en su constitución, en Latinoamérica en cambio "queda casi todo por hacer" (Lenz 1909: 10). En particular, Lenz declara el interés especial que reviste el folklore de Chile:

No sólo se trata de averiguar en qué consiste lo particular del pueblo chileno, en qué se distinguen de sus hermanos sud-americanos. Hai que investigar cuáles elementos fueron traídos de la patria común, España; cómo se desarrollaron i se diferenciaron en cada rejion; qué elementos indígenas se aceptaron en la gran mezcla de razas. En ningún país colonizado por europeos hai tanta mezcla de distintas razas con tan feliz resultado. Naturalmente esta circunstancia también dificulta la cuestión, porque muchos puntos del folklore criollo dependerán del folklore de las tribus indias que entraron en mezcla con los españoles. (Lenz 1909: 10)

En este párrafo, así como en el que citamos a continuación, queda manifestado un interés preferente (si no exclusivo) por los grupos subalternos del territorio chileno, que comprenden principalmente al "pueblo" y a los indígenas mapuche, y a estos últimos principalmente en cuanto subsumidos en el pueblo chileno mediante el mestizaje étnico:

Todas las materias que se desarrollan en el "Programa" se refieren directamente al pueblo chileno de habla castellana; pero por supuesto el estudio de los indios puros o ya medio civilizados del sur, del mismo modo deberá ser objeto de investigaciones nuevas, i de hecho una gran parte de las costumbres i creencias del chileno no se pueden comprender ni explicar sin conocer al indio. (Lenz 1909:12)

Por otra parte, Lenz cree que en Chile están dadas varias condiciones favorables para el desarrollo de esta disciplina: la principal es que existen "profesores de castellano i de idiomas titulados en el Instituto Pedagógico ya iniciados en los requisitos científicos de tales trabajos" (Lenz 1909: 12); 
con esto se refiere, claro, a los formados bajo su propio magisterio (y el de su colega lingüista Federico Hansen) en las dos décadas anteriores. Es interesante acá el planteamiento de que las habilidades técnicas idóneas para recoger materiales folklóricos se atribuyan a profesores entrenados en métodos y teorías de las ciencias del lenguaje. Esto no es raro, por supuesto, ya que los materiales tienen manifestación fundamentalmente discursiva, es decir, se manifiestan como lenguaje en uso. Por ello es que, al final del Programa, se incluye un texto de siete páginas sobre "Fonética chilena i reglas para la transcripcion de documentos en dialecto chileno", que contiene instrucciones para la transcripción y anotación de materiales recogidos en forma oral. Pero además este planteamiento tiene el efecto de poner a la lingüística descriptiva en un lugar central de las disciplinas base del folklore. De hecho, Lenz pone como ejemplo de los primeros avances hechos sobre la materia en el país "publicaciones recientes literarias en dialecto vulgar de Chile", así como "el diccionario de Voces Chilenas", "los Estudios Araucanos, i el diccionario etimolójico de voces chilenas de orijen indio", junto con recopilaciones de "refranes chilenos". (Lenz 1909: 12)

El "Ensayo de programa para estudios del folklore chileno", correspondiente a una presentación que Lenz hizo a la Universidad de Chile en 1905, caracteriza los grandes temas y la estructura jerárquica de los materiales por recoger y conocimientos por producir en el marco de la SFCh. El "Lenguaje vulgar (I: Teoría del idioma [gramática]; II: El material del idioma)" es uno de los cuatro grandes ámbitos de interés del folklore, además de la "Literatura" que también puede considerarse una manifestación lingüística. Cuando Lenz habla de la "teoría del idioma" hay que tener en cuenta que sigue el uso que Andrés Bello había hecho de este sintagma. Años más tarde, en la introducción a La oración y sus partes, Lenz definirá esta área disciplinar: "[L]a gramática, según ya dijo Andrés Bello en el prólogo de su Gramática, es la teoría del idioma o, como otros prefieren decir, la ciencia del idioma, pues contiene la exposición teórica, abstracta, de todos los principios generales que rigen un idioma dado" (Lenz [1920] 1944: 1011; resalte en el original); y añadirá: "el estudio [escolar] de la gramática del idioma patrio no puede tener más elevado propósito que el de hacer ver al alumno cómo se refleja la lógica general del pensamiento humano en un lenguaje determinado" (Lenz [1920] 1944: 14). En el caso de la comunidad hablante de castellano, a pesar de sus diferencias internas ("una lengua literaria, hablada en tan dilatados territorios como la castellana, no puede ser completamente uniforme en todas partes"; Lenz [1920] 1944: 20), Lenz se atreve sin embargo a suponer una comunidad de mentalidad: “. . para que [los profesores] no sigan enseñando la gramática mecánicamente, como se hace a menudo, sino que traten de hacer comprender a sus alumnos cuál 
es el mecanismo del pensamiento castellano". (Lenz [1920] 1944: 20-21; resalte nuestro)

De forma coherente con la concepción que acabamos de explicar, la nota a pie de página que Lenz pone desde el encabezado "Teoría del idioma (gramática)" del Programa explica las razones de la importancia atribuida al estudio del lenguaje en sus principios generales en relación con los intereses del folklore:

El lenguaje en sus elementos gramaticales generalmente no se incluye en el dominio del folklore. Pero, por un lado, es el vehiculo de toda la literatura oral i de consiguiente su conocimiento exacto es indispensable; por otra parte en él no sólo se manifiesta la sicolojía de la nación, sino puede también dar muchas luces sobre al oríjen del pueblo moderno i la cultura primitiva de cada uno de sus componentes. Con razón Wundt le dedica los primeros dos tomos a su Sicolojía Etnica. (Lenz 1909: 17)

Primero, de acuerdo con Lenz, conviene tener un conocimiento acabado del lenguaje vulgar para poder interpretar apropiadamente las manifestaciones discursivas del alma del pueblo; es decir, su estudio tiene una importancia filológica, en el sentido moderno del término (estudio del lenguaje como vehículo de manifestación de monumentos culturales y establecimiento de versiones fidedignas de los textos). Podemos calificar a esta de una importancia trascendente. Segundo, también el estudio del lenguaje vulgar tiene una importancia inmanente: el lenguaje en sí mismo es una vía de conocer la "sicología étnica", la mentalidad de un pueblo. Y de esta importancia también vuelve a emanar otra utilidad trascendente, pero en un nivel distinto: el estudio de la mentalidad también sirve para conocer el origen y la historia de los pueblos. No es necesario insistir en que todos estos provechos que Lenz atribuye a la inclusión del "lenguaje vulgar" entre las esferas mayores de interés de los estudios folklóricos/etnológicos otorgan un claro sentido (gloto)político en el contexto de un Estado-nación en que el nacionalismo cultural campaba como fundamento de las aproximaciones científicas a la naturaleza humana.

A continuación, citamos la caracterización completa que Lenz hace de los ítems específicos que caben dentro del apartado "El lenguaje vulgar":

IV.- El lenguaje vulgar

I.- Teoría del idioma (gramática).

1. La fonética especial de cada provincia.

2. La morfolojía.

3. Construcciones notables de la sintáxis popular (basándose tanto en cuentos, tradiciones i descripciones apuntados según dictado 
de jente sin instrucción escolar, o solo con instrucción elemental, como en observación directa del habla).

4. Derivaciones i composiciones con elementos castellanos (los diminutivos en -ito e-illo, terminaciones como-ero, -azo, -on, etc., etc).

5. Semasiolojía: estudio comparativo del desarrollo del significado desde el castellano del siglo XVI hasta el chileno moderno.

II.- El material del idioma.- Colección de las voces castellanas.

1. Los elementos castellanos que han cambiado de significado, especialmente las denominaciones vulgares de plantas i animales aplicadas a objetos indígenas de Chile, tratando de indicar la razón por qué se ha dado tal nombre a tal planta o animal. (Compárese: roble, leon, zorro, trucha, parrilla, olivillo, peralillo, etc.)

2. Las voces de oríjen indígena. (Este estudio ya está hecho en lo esencial i actualmente imprimiéndose).

3. Estudio negativo del diccionario castellano, enumerar, ordenándolas según ideas, las voces que figuran en los diccionarios i no se conocen entre la jente del pueblo chileno, distinguiendo los elementos doctos (latino-griegos) i los propiamente castellanos tradicionales.

4. Vocabularios especiales para cada oficio se darán junto con las descripciones de los mismos. (Véase III C. i D.) Tambien conviene estudiar aparte los reniegos i los gritos callejeros; el lenguaje de los pillos (la coa), los apodos i sobrenombres entre pillos, suplementeros i otra jente baja, etc., etc.

En el punto II.2 está considerado explícitamente el contenido del Diccionario etimológico. Cabe destacar también que lo que le interesa al Lenz folklorólogo de la "teoría del idioma" en realidad ni siquiera se circunscribe a lo que es general de la nación (el "idioma patrio"), sino a lo particular de ciertos grupos socioculturales, como puede verse también muy claramente en los centros de interés considerados en el "Material del idioma". Así se explica la preferencia por lo dialectal: "la fonética especial de cada provincia", y no la fonética general del país; así como de este modo se entiende el énfasis en las construcciones sintácticas "notables" del habla popular. Puede verse aquí una perspectiva diferencial (foco en las diferencias que una variedad tiene respecto de un punto de referencia, habitualmente el estándar) más que integral (foco en todo lo que existe en uso en una variedad), retomando la distinción que a propósito de los diccionarios americanos propuso Günther Haensch, y que, como destaca Zimmermann, "no se trata de dos métodos técnicos, sino de orientaciones radicalmente distintas consecuencia de 
usos diferentes del diccionario y de dos concepciones glotopolíticas del diccionario asimismo distintas". (2018: 123)

Los diccionarios diferenciales "no pueden contribuir [...] a la estandarización de las variedades nacionales del español en América, sino que perpetúan la idea de que estas tienen menor valor" (Zimmermann 2018: 135). Esta es una idea clave que fundamenta nuestra discrepancia respecto de la interpretación que hace Chávez (2011) sobre el rol de Lenz en la codificación de una lengua nacional. Creemos que lo que dice Zimmermann sobre los diccionarios podría decirse en general de la descripción lingüística cuando esta adopta una perspectiva diferencial, y esto tiene consecuencias para interpretar la razón de que la SFCh haya puesto foco en lo diferencial en lugar de aspirar a levantar caracterizaciones integrales del uso lingüístico del pueblo chileno. Lo interesante es que atraer la distinción diferencial/integral permite apreciar mejor el elemento valorativo que hay en la preferencia por estudiar lo popular, cristalizado de forma muy clara en el Diccionario etimológico de Lenz.

\section{LA REPRESENTACIÓN IDEOLÓGICA DEL LENGUAJE EN EL DICCIONARIO ETIMOLÓGICO}

Situado en el marco del proyecto de construcción de conocimiento de la $\mathrm{SFCh}$, el Diccionario etimológico de Lenz cobra un sentido adicional al que aporta la hipótesis araucanista (pensada como contribución a la lingüística románica y a la lingüística general). Este sentido glotopolítico adicional es el de contribuir al conocimiento del "alma" del pueblo chileno, es decir, al conocimiento de los sectores subalternos. Como lo dice el propio autor: "En una palabra, conoceremos al pueblo por medio de su vocabulario" (Lenz [1905-1910] 1979: 39; resalte nuestro). La circunscripción "nacional" y trascendente a la temática del contacto (de interés más bien para la filología románica), que podría considerarse un síntoma de la resignificación de la obra al situarla en el marco del programa de la SFCh (fuertemente influenciada por el nacionalismo cultural), puede apreciarse asimismo en otros pasajes: "El trabajo que presento es en cierto sentido una contribución a ese futuro diccionario completo de la lengua castellana i más directamente al diccionario nacional chileno" (Lenz [1905-1910] 1979: 22; resalte nuestro); "Escribo para todos los que buscan el significado i el oríjen de tantas palabras que, por mas que se diga, forman parte del patrimonio chileno". (Lenz [1905-1910] 1979: 41; resalte nuestro) 
Por esta razón, es decir, por situar el problema del lenguaje popular en un marco nacional, es que las informaciones más interesantes sobre su representación del lenguaje de los subalternos (en cuyo marco hay que situar la representación del contacto mapuzugun-castellano) se encuentran en sus caracterizaciones de lo que podría llamarse la ecología sociolingüística del castellano chileno. Lenz invierte grandes esfuerzos en aclarar que, aunque destaque el sustrato indígena, lo que está caracterizando es básicamente la lengua que sirve de fundamento (en la lógica romántica) para la existencia de una nación chilena homogénea a pesar de ser resultado de mestizaje. Su deseo es que, al reconocer el sustrato indígena, se difunda una actitud de integración de lo indígena, pero integración en un sentido asimilador y por lo mismo erradicador (por ello es relevante que se construya el elemento indígena como parte de un pasado). Más que apuntar a una solución multicultural de convivencia, la postura de Lenz es eminentemente monoglósica por activar el dogma de la homogeneidad. (Del Valle y Gabriel-Stheeman 2004):

Este enorme número de palabras araucanas i quechuas incorporadas en la lengua castellana son como las cicatrices de la lucha jigantesca en que el español de Chile venció al indio de Chile, i lo obligó a aprender un idioma europeo i a formar con él una nacionalidad nueva i firme, la mas sólida $i$ homojénea que se enjendró en suelo americano pisado por español.

Pues esto hai que recordarlo al estranjero que lea este libro. Los que usan el lenguaje del cual el diccionario que sigue forma una parte integrante no son indios sino chilenos puros, de los cuales muchos ni siquiera sospechan que las voces que usan pertenecieron a otra lengua. No se crea que se trate de un lenguaje criollo en el sentido como toma la filología románica la palabra. El lenguaje del último huaso chileno es lingüísticamente castellano puro no obstante las voces indias, como el ingles es lengua jermánica pura no obstante los millares de voces francesas i latinas asimiladas. Ni siquiera el bajo pueblo recuerda o conoce la lengua del indio.

El chileno no habla mas que un solo idioma, el castellano chileno. Los pocos individuos bilingües que hai en el país (fuera de los europeos recien imigrados) son los indios que ya han aprendido el castellano. [...]. Tampoco debe creer el extranjero que el lenguaje del bajo pueblo chileno sea incomprensible para otros hispano americanos o para los españoles. Lo esencial de la lengua, toda su gramática i las nueve décimas partes de las palabras, entre ellas todas las mas usadas, son castellanas puras. [...] Ojalá que mis estudios contribuyan a hacer simpática la figura del indio, para que se comprenda que esos millares - mas de cincuenta, quizas ochenta- no deben ser aniquilados cuanto ántes, sino civilizados $i$ asimilados a la nación chilena. (Lenz [1905-1910] 1979: 41-42; resaltes nuestros) 
Dado este marco nacionalista homogeneizante y asimilatorio que declara que en Chile solo se habla castellano, es interesante profundizar un poco en qué entiende Lenz por castellano: "es la lengua jeneral i comun de la jente culta del pais, incluyendo las palabras técnicas de los artesanos i los nombres de historia natural" (Lenz [1905-1910] 1979: 14), mientras que "palabras que solo corren entre los habitantes de una provincia, si están en uso en la buena sociedad, son provincialismos de la lengua castellana" (Lenz [19051910] 1979: 14-15) y "como dialectal sólo debemos considerar un término que, usado por la jente sin educacion escolar o por los que escasamente saben leer i escribir, no tenga curso en la conversacion de jente culta" (Lenz [1905-1910] 1979: 15). Cabe destacar que Lenz establece una separación limpia entre castellano propiamente tal y dialecto, mediante un criterio al fin y al cabo similar al criterio sociocultural de Bello: castellano hablan las personas educadas, mientras que dialecto hablan las personas sin educación. En este sentido, se puede ver una jerarquía marcada entre ambos constructos, apoyados en la dimensión jerárquica que históricamente ha tenido la distinción entre lengua (superior) y dialecto (inferior). Metonímicamente, por el valor indicial de ambas formas de lenguaje, quedan sometidas a la misma jerarquización los sectores dominantes (educados, superiores) y los subalternos (no educados, inferiores), cumpliéndose así el efecto glotopolítico de la representación metalingüística. Esto no puede hacernos perder de vista, que, a diferencia de Bello (a quien Lenz suele oponerse polémicamente; $c f$. Gómez Asencio y Rojas 2019), el alemán hace el gesto de querer incorporar al subalterno en el imaginario de la nación, aunque sea para subsumirlo y a la vez dar mayor legitimidad al orden vigente, por el afán democratizante del gesto.

En otras partes de los textos preliminares del Diccionario, esta jerarquización se reitera a propósito del componente léxico de la lengua en particular, tema específico de la obra. Primero, Lenz ofrece una "clasificación" de las palabras que componen el castellano general, atendiendo, por un lado, a criterios geodialectales y, por otro, a criterios socioestilísticos ("la esfera de cada palabra"). Según el criterio geodialectal, establece la siguiente partición:

I voces pan-castellanas

II $a$. voces pan-españolas (usadas en toda la España).

$b$. voces pan-americanas (usadas en toda la América hispana). $c$. voces nacionales americanas (usadas en una o alguna de las repúblicas).

1. voces mejicanas

2. voces guatemaltecas, etc., etc. 
En cada país de mayor estension habrá que distinguir todavía los provincialismos (así en Chile los provincialismos del norte, centro, sur, Chiloé, etc.). (Lenz [1905-1910] 1979: 20-21)

En este caso, el ordenamiento no necesariamente podría atribuirse a una jerarquización valorativa; más bien, se puede tratar meramente de una relación de inclusión, de lo más general a lo más específico. Sin embargo, considerando que una cosa es la intención del autor y otra cómo sus palabras sean interpretadas, y considerando también que el lector de la época probablemente interpretaba tal clasificación a partir del ideologema de que una voz, mientras más provincial sea, menos se presta al uso cultivado de la lengua ( $c f$. Rojas 2017), bien podríamos entender que dicho ordenamiento porta (como sentido en potencia) una valoración positiva "hacia arriba" y negativa "hacia abajo".

La segunda parte de la clasificación (las "esferas"), como decíamos, Lenz la hace de acuerdo con los criterios socioestilísticos:

I estilo literario con subdivisiones: poesía i estilo elevado; filosofía, astronomía, etc., estilo científico; bellas artes; administración pública, etc., tecnicismo de la industria, del comercio, términos de guerra, marina etc.

II esfera jeneral de la vida pública i privada, lenguaje comun escrito i de conversacion; este grupo que comprende la mayor parte de todas las palabras comunes no necesitaría indicacion especial

III lenguaje técnico de los oficios, industria casera, comercio al menudeo, etc.

IV términos vulgares de historia natural

$\mathrm{V}$ estilo familiar

VI lenguaje vulgar, dialecto

VII voces bajas que se consideran indecentes

VIII lenguaje especial de ciertos gremios, especialmente criminales, que quiere ser incomprensible para los demas, jermanía, etc.

[...] Abunda decir que para la justa apreciacion de cada voz será útil saber si es debida a una lengua indíjena, a algun idioma estranjero, si es una derivacion de base castellana, o si se trata de una palabra antigua con significado nuevo. (Lenz [1905-1910] 1979: 21-22)

Acá, a diferencia del caso anterior, no podría defenderse una relación jerárquica de inclusión, de modo que se hace más transparente la jerarquía valorativa que implica, entendiendo que las esferas I a $\mathrm{V}$ gozan de mayor valía, pues forman parte por derecho propio del castellano, del lenguaje común nacional, tal como lo había definido Lenz antes; mientras tanto, 
las esferas VI a VIII (que es donde hay que ubicar la mayor parte de los indigenismos léxicos registrados por Lenz) reciben implícitamente una valoración negativa, por quedar de alguna manera fuera (o al menos en la periferia) de ese lenguaje que sirve de fundamento a la nación, y esto debido a la indeseabilidad de sus atributos: vulgaridad, indecencia, incomprensibilidad, condensado este último en la denominación (ideológicamente cargada) de dialecto. Y nótese, además, que para cada una de las esferas es importante contar con el dato del origen de la palabra, lo cual justifica el proyecto lexicográfico etimológico de Lenz.

En un mundo todavía marcado por el pensamiento evolucionista, no podemos dejar de sospechar que la condición indígena significaba una "mancha" en la reputación de una palabra, de modo similar a lo común en la lexicografía normativista chilena del siglo XIX. La "justa apreciación de cada voz" pasa en buena medida por la identificación de su generalidad geográfica, su esfera y su origen. De esta manera, el Diccionario etimológico se erige como un dispositivo de control: de modo análogo a la manera en que los diccionarios normativos chilenos del siglo XIX no pretendían simplemente describir los "chilenismos", sino precisamente consignar su condición de chilenismo, es decir, de vocablo (en principio) "incorrecto", el Diccionario de Lenz sirve para reconocer el origen indígena de centenares de palabras de las esferas más bajas del castellano chileno. Este reconocimiento, lejos de cumplir una función exclusivamente objetiva de "conocer", es un mecanismo de distinción, de construcción de otredad, subalternidad y subordinación en los sujetos que las emplean. A pesar de la similitud entre ambos dispositivos, debe considerarse el matiz de que, mientras los diccionarios normativos chilenos del XIX pretenden segregar, la obra de Lenz queda mejor caracterizada por la intención de incorporar para otorgar un lugar subalterno.

De este modo, nuestra conclusión respecto de la representación del lenguaje contenida en los preliminares del Diccionario etimológico de Lenz es que, así como lo indígena se construye como asimilado en lo nacional, también lo subalterno, lo popular (que es donde precisamente predomina la influencia indígena) se representa como ineludiblemente inscrito en el marco más amplio de la nación, que es donde el lenguaje de los subalternos en general adquiere un "valor" marcado, es decir, un significado relacional frente al resto de los elementos que conforman el castellano chileno. Por ser un valor de signo negativo, cumple la función (gloto)política de naturalizar la subordinación material de los subalternos, relación de poder que es elemento configurante de su integración a la nación chilena. 


\section{CONSIDERACIONES FINALES}

En el presente trabajo nos hemos propuesto, desde un enfoque glotopolítico acerca de la relación entre poder y conocimiento sobre el lenguaje, incorporar a la indagación sobre el Diccionario etimológico de Rodolfo Lenz la consideración de algunos elementos habitualmente soslayados de su contexto de producción y circulación: la inscripción de esta obra en el proyecto intelectual de la Sociedad de Folklore Chileno y la recepción de la obra en el ámbito especializado, tanto nacional como internacional. Para ello, hemos recurrido tanto a materiales publicados como a documentos inéditos conservados en el Fondo Lenz de la Universidad Metropolitana de Ciencias de la Educación.

A partir de estos materiales, proponemos pensar en el Lenz lexicógrafoindigenista-folklorólogo, autor del Diccionario etimológico, como un "agente colonial", tal como entiende este concepto Joseph Errington, es decir, como un especialista que, por un lado, "devices necessary conduits for communication across lines of colonial power" (Errington 2008: 4), pero que, sobre todo, en el Diccionario, "made language objects of knowledge, so that their speakers could be made subjects of power" (Errington 2008: $3)$. Cabe precisar que para atribuir este rol a Lenz tenemos que entender que colonización se aplica no solo a los procesos de expansión protagonizados por los imperios occidentales desde el siglo XVI, sino también a aquellos mediante los que las repúblicas hispanoamericanas extendieron sus territorios físicos y simbólicos durante el largo siglo XIX en el marco de los procesos de construcción de Estado-nación.

En el caso de la etnología, si bien funciona dentro de la lógica Europacentro-teoría / América-periferia-práctica, por "el estatuto doble de las repúblicas latinoamericanas, colonizadas y colonizadoras, la distinción centro/periferia adquiere una lógica fractal" (Pavez 2015: 46), gracias a la cual "el centro de una periferia" puede llegar a "ejerce[r] sus propios imperios" (ibid.). Si bien esta afirmación vale para la división internacional del trabajo etnográfico, bien puede aplicarse para la relación de colonización interna (usando una frase de Pablo González Casanova, cit. en Rivera Cusicanqui 2019: 112-13) que establece el Estado-nación chileno respecto de los sujetos subalternos, peligrosamente fronterizos y periféricos, a punto de "salirse" de la nación.

Lenz es, por lo anterior, un actor social que posibilita que poder (estatal) y conocimiento se encuentren imbricados en torno al lenguaje, transformándose en una figura de dimensiones radicalmente glotopolíticas, así como se presenta como radicalmente glotopolítica, por metonimia, la labor 
investigadora sobre el lenguaje de los sectores subalternos emprendida por la SFCh y manifestada en particular en su Diccionario etimológico. La SFCh se constituyó como una entidad que, con apoyo del Estado (representado básicamente por el Instituto Pedagógico) y al mismo tiempo al servicio de este, se propuso principalmente promover y facilitar los estudios sobre el folklore en Chile. Estos estudios se entendían como de naturaleza científica de acuerdo con un enfoque positivista, es decir, basándose en el estudio de material empírico y la clasificación y análisis sistemático de los materiales. Siguiendo los dictados de la ciencia antropológica de la época (la etnología), la SFCh se proponía contribuir a conocer la "vida síquica" o mentalidad del pueblo chileno desde una matriz evolucionista que implicaba que el conocimiento de los sectores más "atrasados" (como los sectores populares o los pueblos indígenas) permitiría arrojar luz sobre etapas pasadas de la humanidad así como facilitar el avance de la civilización y el progreso. El folklore sería una de las manifestaciones materiales (por tanto, observables empíricamente) de esa mentalidad (no observable directamente), y además una manifestación que corría riesgo de desaparecer bajo el avance arrollador del progreso moderno, de modo que la ciencia del folklore era una actividad de rescate de ese patrimonio.

En el delineamiento que ofrece Lenz en el programa, la lingüística descriptiva ocupa un rol fundamental en el levantamiento de materiales empíricos, no solo por manifestarse el folklore a través del lenguaje (como discursos: relatos, adivinanzas, poesía popular, etc.), sino porque el "lenguaje vulgar" (el de los grupos subalternos) reviste un interés inmanente al ser reflejo fiel del pensamiento popular. Este estudio del lenguaje subalterno supone una perspectiva diferencial que implica a su vez una visión jerarquizante donde dicho lenguaje se define negativamente en su relación de diferencia (conceptualizada como déficit) respecto del lenguaje "normal" (el de las clases dominantes). El Diccionario de Lenz cobra un sentido y desempeña una función glotopolítica en el marco de esta relación específica entre construcción de conocimiento especializado y construcción de alteridad y subordinación simbólica.

De acuerdo con lo dicho, las representaciones de los discursos analizados son ideológicas en la medida en que sirven a los intereses políticos de un grupo social específico, y, como suele suceder con la ideología dominante, por presentarse bajo una forma de discurso "verdadero", el que, por el contexto histórico-situacional específico en que se sitúan sus autores (modernización del Estado sobre principios positivistas), abraza el cientificismo como garante de dicha veracidad. De esto es síntoma importante el que, como vimos, la legitimidad de la obra la haya representado su propio autor sobre la base de la percepción de cientificidad por parte de la república internacional de 
la ciencia. La ciencia del lenguaje encabezada en Chile por Rodolfo Lenz, entonces, desempeña un papel importante en la afirmación de una posición hegemónica por parte de las élites chilenas castellanohablantes y de una situación de subordinación para el mapuzugun y las variedades de castellano influidas por el contacto con este.

\section{REFERENCIAS BIBLIOGRÁFICAS}

\section{FUENTES PRIMARIAS}

\subsection{Obras de Lenz}

Lenz, Rodolfo. [1892-1893] 1940. Estudios chilenos (fonética del castellano de Chile). El español en Chile. Trabajos de Rodolfo Lenz, Andrés Bello y Rodolfo Oroz, pp. 87-258. Buenos Aires: Universidad de Buenos Aires.

[1893] 1940. Para el conocimiento del español de América. El español en Chile. Trabajos de Rodolfo Lenz, Andrés Bello y Rodolfo Oroz, pp. 211-258. Buenos Aires: Universidad de Buenos Aires.

[1905-1910] 1979. Diccionario etimológico de voces chilenas derivadas de lenguas indígenas americanas. Edición dirigida por M. Ferreccio Podestá. Santiago: Universidad de Chile.

1909. Programa de la Sociedad de Folklore Chileno. Santiago: Imprenta y Encuadernación Lourdes.

[1920] 1944. La oración y sus partes. Estudios de gramática general y castellana. $4^{\mathrm{a}}$ ed. Santiago de Chile: Editorial Nascimento. [Al cuidado del P. Alfonso M. Escudero]. 1927. Problemas del diccionario castellano en América. Buenos Aires: Universidad de Buenos Aires.

[1937] 1940. Advertencia del autor [a la traducción de "Estudios chilenos"]. El español en Chile. Trabajos de Rodolfo Lenz, Andrés Bello y Rodolfo Oroz, pp. 81-82. Buenos Aires: Universidad de Buenos Aires.

s/f. Anexo segundo al Diccionario Etimolójico de voces chilenas derivadas de lenguas indíjenas americanas. Publicación privada del autor.

\subsection{Reseñas del Diccionario etimológico}

Cejador, Julio. 1907. Bibliografía sobre el Castellano de América. La España Moderna 224: 5-26.

Dinigo, JuAn M. s/f. [Reseña de Rodolfo Lenz, Los elementos indios del Castellano de Chile]. Revista de la Facultad de Letras y Ciencias (U. de La Habana) XIII (1): 95-97.

Eметн, OMer. 1910. El nombre de Chile y otros nombres. El Mercurio (Santiago), domingo 18/09/1910.

Espinosa, Aurelio M. 1910. [Reseña de Rodolfo Lenz, Los elementos indios del Castellano de Chile...]. Revue de Dialectologie Romane II (3-4): 421-424.

Rivet, Paul. 1911. [Reseña de Diccionario etimológico de las voces chilenas...]. Journal de la Société des Américanistes 8: 337. 
Zauner, Adolf. 1908. [Reseña de Rodolfo Lenz, Los elementos indios del Castellano de Chile...]. Literaturblatt für germanische und romanische Philologie I: 25-28.

\section{BIBLIOGRAFÍA SECUNDARIA}

Arnoux, Elvira. 2000. La Glotopolítica: transformaciones de un campo disciplinario. Lenguajes: teorías y prácticas, pp. 3-27. Buenos Aires: Instituto Superior del Profesorado "Joaquín V. González".

2006. Análisis del discurso: modos de abordar materiales de archivo. Buenos Aires: Santiago Arcos.

y SusAna Nothstein. 2014. Glotopolítica, interacción regional sudamericana y panhispanismo. En Elvira Arnoux y Susana Nothstein (eds.). Temas de Glotopolítica. Integración regional sudamericana y panhispanismo, pp. 9-29. Buenos Aires: Biblos.

Aronowitz, Stanley. 1988. Science as power. Discourse and ideology in modern society. Minneapolis: University of Minnesota Press.

Bourdieu, Pierre y Luc BoltansKi. 2009. La producción de la ideología dominante. Trad. H. Cardoso. Buenos Aires: Nueva Visión.

Bustamante, Jesús. 2014. La institucionalización de las ciencias antropológicas en las nuevas naciones y el papel de los museos. En Sandra Carreras y Katja Carrillo Zeiter (eds.). Las ciencias en la formación de las naciones americanas, pp. 165-200. Madrid/Frankfurt: Iberoamericana/Vervuert.

Chávez, Soledad. 2011. Ideas lingüísticas de Lenz en los paratextos de su Diccionario etimológico de las voces chilenas derivadas de lenguas indígenas americanas: vigencia y urgencia en el español de Chile. Lenguas Modernas 38: 83-106.

Chen, Wenge. 2019. Towards a discourse approach to Critical Lexicography. International Journal of Lexicography 32 (3): 362-388.

Concha Ferreccio, Pablo. 2015. La genealogía filológica: regionalismo literario y comunidades imaginadas en Brasil y Chile. Tesis de Magíster, U. de Chile.

Dannemann, Manuel. 2010. Tres buscadores de la chilenidad: Lenz, Laval y Vicuña Cifuentes. Anales de Literatura Chilena 11 (14): 57-92.

Del Valle, José. 2017. La perspectiva glotopolítica y la normatividad. Anuario de Glotopolítica 1: 17-39.

2019. Departments and disciplinary gatekeeping: the sociolinguistics of Spanish in US Academia. Insights from the Social Sciences, https://items.ssrc.org/departments-anddisciplinary-gatekeeping-the-sociolinguistics-of-spanish-in-us-academia/

y LUIS GABRIEL-STHEEMAN. 2004. Nacionalismo, hispanismo y cultura monoglósica". En José del Valle y Luis Gabriel-Stheeman (eds.). La batalla del idioma. La intelectualidad hispánica ante la lengua, pp. 15-33. Frankfurt/Madrid: Vervuert/Iberoamericana.

y Vitor Meirinho-Guede. 2016. Ideologías lingüísticas. En Javier Gutiérrez-Rexach (ed.). Enciclopedia de lingüistica hispánica, vol. 2, pp. 622-631. London \& New York: Routledge.

EnNis, Juan Antonio. 2016. Rodolfo Lenz: economías de la lengua y políticas de la lingüística. Boletín de Filología 51 (1): 117-145.

ERrington, JosePh. 2008. Linguistics in a colonial world. A story of language, meaning, and power. Malden: Blackwell.

Escudero, Alfonso M. 1963. Rodolfo Lenz. Thesaurus 18 (2): 445-484.

Ferreccio, Mario. 1979. Presentación. En Rodolfo Lenz, Diccionario etimológico de voces chilenas derivadas de lenguas indígenas americanas, pp. 8-24. Edición dirigida por Mario Ferreccio Podestá. Santiago: Universidad de Chile. 
Gómez Asencio, José J. 2016. Categorías en La oración y sus partes (1920) de Rodolfo Lenz: Clases. Boletín de Filología 51 (1): 147-185.

y Darío Rojas. 2019. Rodolfo Lenz (1920) frente a la Gramática de la lengua castellana (1847) de Andrés Bello. RLA. Revista de Lingüística Teórica y Aplicada 57 (1): 105-124.

Heller, Monica y Bonnie McElhinny. 2017. Language, capitalism, colonialism: toward a critical history. Toronto: University of Toronto Press.

KoERner, E. F. Konrad. 2001. Linguistics and Ideology in 19th and 20th Century Studies of Language. En René Dirven y Bruce Hawkins (eds.). Language and Ideology: Volume 1: theoretical cognitive approaches, pp. 253-276. Amsterdam: John Benjamins.

Laurendeau, Paul. 1990. Theory of Emergence: toward a historical-materialistic approach to the history of linguistics. En John E. Joseph y Talbot J. Taylor (dirs.). Ideologies of language, pp. 206-220. London/New York: Routledge.

Meirinho-Guede, Vitor y José del Valle. 2018. "Español” (y “castellano”). En Barbara Cassins. Vocabulario de las filosofias occidentales. Diccionario de los intraducibles, 2 vols., edición en español coordinada por Natalia Prunes y Guido Herzovich. México: Siglo XXI.

Mora, HÉctor. 2016. La institucionalización de las ciencias antropológicas en Chile. Una aproximación a las dinámicas socio-organizativas y cognoscitivas en la conformación del espacio científico (1860-1954). Tesis de doctorado, Universidad Nacional de La Plata.

y Rodrigo VÁsquez. 2018. La ciencia y lo "araucano" como ideas fuerza: antropología y emergencia del "araucanismo" en Chile. En Héctor Mora y Mario Samaniego (eds.). El pueblo mapuche en la pluma de los araucanistas. Seis estudios sobre construcción de la alteridad, pp. 22-87. Santiago: Ocho Libros.

Norambuena, Francisca. 2016. Ideologías lingüísticas en el 'Diccionario de chilenismos' (1901-1918) de Manuel Antonio Román. Tesis de licenciatura, U. de Chile.

Pavez, Jorge. 2015. La lengua de Chile: Rodolfo Lenz entre chilenos y mapuches. En Laboratorios etnográficos. Los archivos de la antropología en Chile (1880-1980), pp. 67-167. Santiago: Ediciones Universidad Alberto Hurtado.

Pecheux, Michel. [1975] 2017. Las verdades evidentes. Lingüística, semántica, filosofía. Trad. de Mara Glozman, Pedro Karczmarczyk, Guadalupe Marando y Margarita Martínez. Buenos Aires: Ediciones del CCC.

Rivera Cusicanqui, Silvia. 2019. Chi'ixinakaxutwixa. A reflection on the practices and discourses of decolonization. Language, Culture and Society 1 (1): 106-119.

RoJAs, Darío. 2017. Representaciones del cambio lingüístico en Chile durante el siglo XIX: “¿progreso o decadencia?”. Literatura y Lingüistica 36: 243-262.

y TANia Avilés. 2012. La recepción de Voces usadas en Chile (1900) de Aníbal Echeverría y Reyes entre sus contemporáneos. Boletín de Filología 47 (2): 149-175.

y TANIA AviLÉs. 2015. Ideologías lingüísticas en un debate del siglo XIX chileno: los comentaristas del Diccionario de chilenismos de Zorobabel Rodríguez. Línguas e Instrumentos Lingüisticos 35: 53-72.

SÁnchez, Gilberto. 2013. El Dr. Rodolfo Lenz, primer investigador científico de la lengua y cultura mapuches. Lenguas Modernas 42 (2): 99-113.

Sousa, Silvio Moreira de, y Johannes MücKe. 2016. Addendum to Networking and obstacles to the development of the language sciences as reflected in the correspondence of Rodolfo Lenz and Hugo Schuchardt. History and Philosophy of the Language Sciences. https:// hiphilangsci.net/2016/02/17/networking-and-the-obstacles-to-the-development-ofthelanguage-sciences/

Subercaseaux, Bernardo. 2007. Raza y nación: el caso de Chile. A Contracorriente 5 (1): 29-63. 
Swiggers, Pierre. 2018. De la ideología de la(s) lengua(s) a la(s) ideología(s) de la lingüística. Circula: Revue d'Idéologies Linguistiques 8: 70-101.

Thompson, John B. 1984. Studies in the theory of ideology. Berkeley/Los Angeles: University of California Press.

VelLeman, BARRY. 2008. La imagen y los ecos del lingüista profesional: la correspondencia de Rodolfo Lenz. RLA. Revista de Lingüistica Teórica y Aplicada 46 (1): 11-28.

Zimmermann, Klaus. 2018. Lexicografía diferencial y lexicografía integral. En María Álvarez de la Granja y Ernesto González Seoane (eds.). Léxico dialectal y lexicografía en la Iberorromania, pp. 121-144. Madrid/Frankfurt: Iberoamericana/Vervuert.

ZúÑIga, Fernando y Aldo Olate. 2017. El estado actual de la lengua mapuche, diez años después. En Isabel Aninat, Verónica Figueroa y Ricardo González (eds.). El pueblo mapuche en el siglo XXI. Propuestas para un nuevo entendimiento entre culturas en Chile, pp. 343-374. Santiago: CEP. 